\title{
Synergy Between Aedes aegypti Trypsin Modulating Oostatic Factor and $\delta$-Endotoxins
}

\author{
Dov Borovsky $^{*}, 1$, Vadim Khasdan ${ }^{2}$, Sabine Nauwelaers ${ }^{1}$, Clara Theunis ${ }^{1}$, Lien Bertie0r ${ }^{1}$, Eitan Ben- \\ Dov $^{3,4}$ and Arieh Zaritsky ${ }^{2}$ \\ ${ }^{1}$ University of Florida-IFAS, Florida Medical Entomology Laboratory, $2009^{\text {th }}$ St SE, Vero Beach Florida, 32962 USA \\ ${ }^{2}$ Department of Life Sciences Ben-Gurion University of the Negev, P.O.Box 653, Be'er-Sheva 84105, Israel \\ ${ }^{3}$ The National Institute for Biotechnology, Ben-Gurion University of the Negev, P.O. Box 653, Be'er-Sheva 84105 Israel \\ ${ }^{4}$ Achva Academic College, MP Shikmim, 79800, Israel
}

\begin{abstract}
Starved first instar Aedes aegypti larvae were 35-fold more sensitive to Bacillus thuringiensis subsp. israelensis (Bti) toxins than fed larvae. Feeding larvae Pichia pastoris yeast cells expressing tmfA (synthetic gene coding for the Trypsin Modulating Oostatic Factor of Ae. aegypti) together with Escherichia coli cells expressing Bti toxin genes ( cry $4 A a$, cryl1Aa, cyt $1 A a$ and $p 20$ ) indicate that TMOF and Cry toxins are synergisitic. tmfA was cloned and expressed in the cyanobacterium Anabaena PCC 7120 and the hormone was purified by HPLC and identified by ELISA. The amount of TMOF synthesized by Anabaena was low $\left(0.5-1 \mu \mathrm{g}\right.$ in $10^{8}$ cells). P. pastoris, which synthesizes high amounts of heterologous proteins in the presence of methanol and is readily consumed by mosquito larvae, was genetically engineered to produce more TMOF. Codon-optimized synthetic genes, cryllAa-tmfA and gst-cryl1Aa-tmfA, that were cloned into P. pastoris and fed to Ae. aegypti larvae caused $87.5 \%$ mortality in 5 days. GST (glutathione-S-transferase) enhanced the activity of Cry $11 \mathrm{~A}-\mathrm{TMOF}$ and protected it from heat denaturation. Cell free extracts of recombinant $P$. pastoris cells killed $40 \%$ of tested $4^{\text {th }}$ instar larvae within $24 \mathrm{~h}$, and mass spectra analysis confirmed that the recombinants synthesize Cry11Aa. This report shows for the first time that Cry toxins and TMOF are synergists to Ae. aegypti larvae when jointly fed or expressed in recombinant $P$. pastoris.
\end{abstract}

Keywords: TMOF, Cry toxins, mosquito larvae, Anabaena, Pichia pastoris, genetic engineering, bio-control.

\section{INTRODUCTION}

Mosquitoes are vectors of major diseases such as malaria, dengue and encephalitis, and are nuisance in temperate zones. Mosquito control programs that solely rely on chemical insecticides often cause ecological problems and select for resistance due to frequent applications [1]. Thus, mosquito control relying on environmentally friendly insecticides is desired.

Trypsin Modulating Oostatic Factor (TMOF), a decapeptide hormone originally purified from the ovaries of female Aedes aegypti [2], inhibits the biosynthesis of trypsin- and chymotrypsin-like enzymes in the midgut epithelial cells of female and larval mosquitoes by a translational control mechanism [3, 4] stopping food digestion. The lack of free amino acids liberated from the blood meal in adult females or from digested proteins liberated in the larval gut causes inhibition of egg development (sterility) to adults and anorexia and death to larval mosquitoes, respectively $[4,5]$. TMOF traverses the gut, enters the hemolymph, binds a TMOF specific

*Address correspondence to this author at the Florida Medical Entomology
Laboratory, University of Florida-IFAS, $2009^{\text {th }}$ St SE, Vero Beach, Florida
32962 USA; Tel: 772-778-7200; Fax: 772-778-7205; E mail: dobo@ufl.edu

$1875-4147 / 10$ receptor(s) on the epithelial cells, and stops trypsin biosynthesis and egg development [4-8].

Mosquito larvae synthesize trypsin-like enzyme(s) in their gut as major digestive protease(s). TMOF expressed on the coat protein of Tobacco Mosaic Virus that was fed to mosquito larvae caused anorexia and death at a low dose (1 ng per larva) [4]. Thus, orally fed TMOF can be used as an effective larvicide against many mosquito species [4, 9]. Using a synthetic TMOF to control mosquito larvae is, however, expensive and inefficient because it is readily soluble in water, whereas mosquito larvae are filter feeders [10]. On the other hand, expressing TMOF in bacterial, algal and yeast cells that are readily eaten by larvae is a simple, efficient and safe way to control mosquitoes.

Bacillus thuringiensis subsp. israelensis (Bti) is the first subspecies of $B$. thurengiensis $(B t)$ that was found and used as an effective biological control agent against larvae of many mosquito and black fly species [11]. Its Cry toxins are per os poisons; they bind to larval midgut causing rapid death, and hence are considered safe larvicides that do not damage the environment [12]. Low probability of developing resistance has been observed in field populations of mosquitoes despite 25 years of extensive field usage [13, 14].

Field persistence of current preparations of Bti is unfortunately low [12], but could be improved by expressing 
the toxin-encoding genes in heterologous organisms that are readily eaten by mosquito larvae and grow in larval breeding habitats. Alternatively, genetically modified organisms can be killed, formulated, and then released into the environment. Encapsulating potential larvicides inside live or dead cells would protect the toxins from degradation by sunlight. Proper formulation will keep these cells afloat in water allowing the larvae to feed on them $[15,16]$. Genetic engineering of cyanobacteria can overcome the low efficacy and short half-life in nature of current formulations [17]. Indeed, transgenic strains of the nitrogen-fixing filamentous cyanobacterium Anabaena PCC 7120 expressing combinations of Bti genes (cry4Aa, cryl1Aa, cytlAa and p20) are highly toxic to mosquito larvae [18-20].

Synergy has been described for bacterial endochitinase and $\delta$-endotoxins by several subspecies of $B t$ against the Egyptian cotton leafworm Spodoptera littoralis larvae [21, 22] and against Ae. aegypti larvae [23]. The diverse physiological effects of Cry toxins and TMOF prompted us to investigate whether TMOF and the $\delta$-endotoxins of $B t i$ can synergistically kill mosquito larvae.
This study reports the cloning and biological activities of Ae. aegypti TMOF in Anabaena and Cry11Aa-TMOF and GST-Cry11Aa-TMOF in Pichia pastoris. In addition, we tested the toxicities of cry4Aa, cryl1Aa and cytlAa expressed in Escherichia coli together with TMOF produced in recombinant $P$. pastoris. The newly engineered transgenic strains are presumed to be environmentally friendly biological-control agents because Cry toxins have been used for three decades with no reported damage to the environment and TMOF has been approved by the EPI. The use of TMOF and Cry toxins in concert will effectively prevent future resistance of these insecticides.

\section{MATERIALS AND METHODS}

\section{Cloning and Expression in Bacteria}

The sub-cloning vector $\mathrm{pBS}-\mathrm{SK} / \mathrm{N}$ and the shuttle vector pRL488 [18] were used to clone tmfA with and without IEGR (trypsin cleavage site), yielding pRVE4-TE and pRVE4-T, respectively (Fig. 1). The E. coli donor strain DH10B (kindly provided by Dr. X. Wu), carrying helper plasmid pRL623 (derivative of pRL528), conjugal plasmid

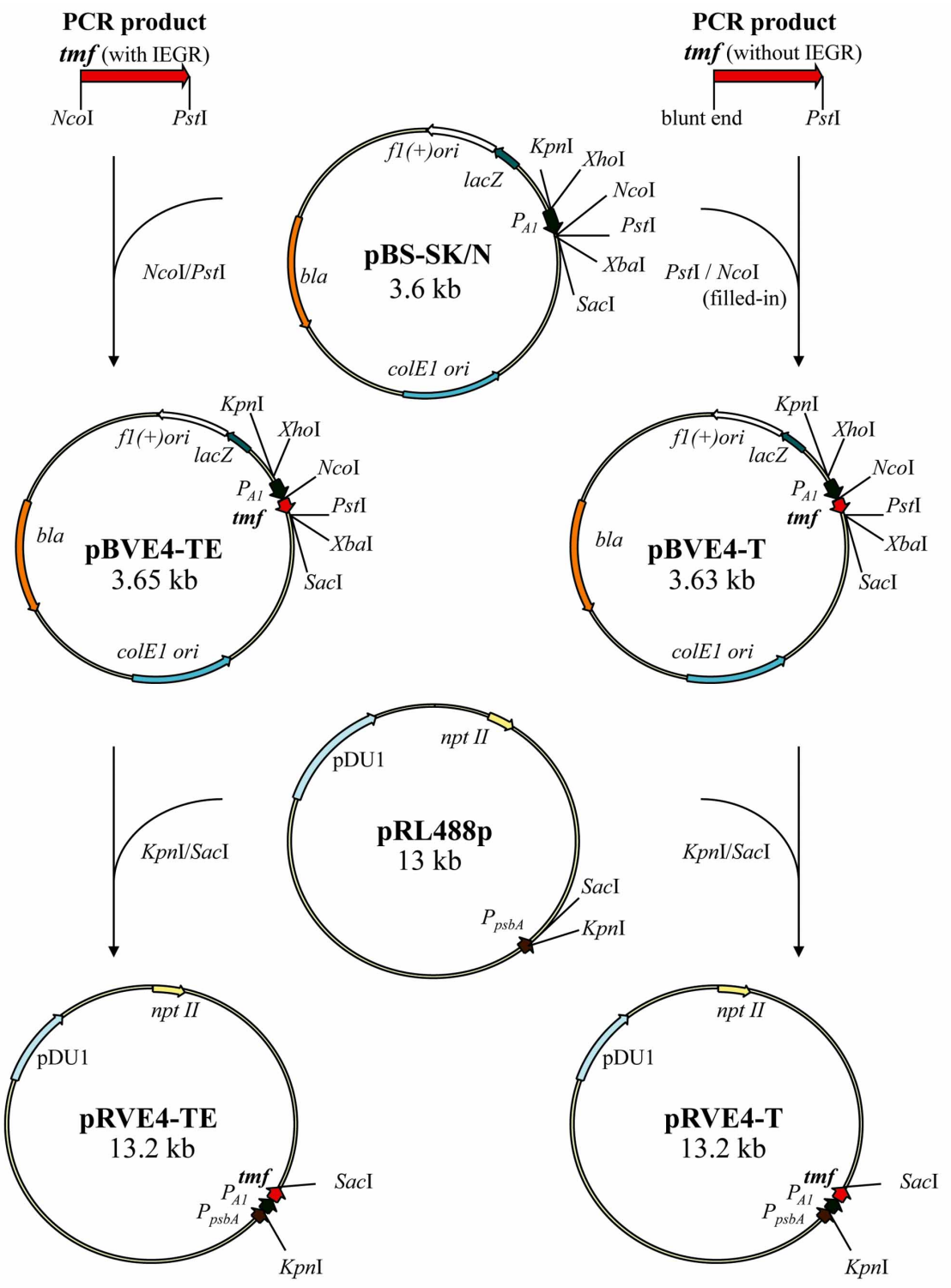

Fig. (1). Cloning of $t m f A$ with and without IEGR (trypsin cleavage site) into the E.coli-Anabeana shuttle vector pRL488p. 
pRL443 (derivative of RP4) and incoming plasmid, were used for biparental conjugation into Anabaena PCC 7120 [24]. The constructed plasmids were transformed into $E$. coli strain XL-Blue MRF' (Stratagene, La Jolla, CA) and Anabaena PCC 7120.

E. coli $\mathrm{DH} 10 \mathrm{~B}$ cells harboring helper, conjugal and either pRVE4-TE or pRVE4-T were mixed with Anabaena PCC 7120 , pre-grown in BG11 liquid medium at $28^{\circ} \mathrm{C}$ under cool white fluorescent light illumination and the mixed suspensions were spread onto nitrocellulose membranes over BG11 agar plates and incubated for $24 \mathrm{~h}$. Membranes were then transferred to selective plates containing neomycin (25 $\mu \mathrm{g} \mathrm{ml}{ }^{-1}$ ). Colonies that appeared after 10 days were transferred into $1 \mathrm{ml} \mathrm{BG11} \mathrm{containing} \mathrm{neomycin} \mathrm{and} \mathrm{grown}$ for two weeks until true ex-conjugants were detected; they were then purified by repeated streaking on agar plates in the presence of neomycin, each was diluted with BG11 containing neomycin and grown as described above. Growth was followed by measuring chlorophyll concentrations in methanol extracts [18]. Existence of inserted genes was confirmed by PCR using appropriate primers.

\section{Cloning and Expression in $\boldsymbol{P}$. pastoris}

A Zeocin-selectable plasmid pPICZB (Invitrogen, Carlsbad, CA) that was used for cloning and expressing heterologous proteins in $P$. pastoris contains an alcohol oxidase 1 promoter $\left(P_{A O X I}\right)$ from $P$. pastoris fused to a multiple cloning site and an $A O X 1$ termination sequence. Fermentation in the presence of methanol $(0.5 \%)$ induces $P_{A O X I}$ to initiate transcription in $\mathrm{KM} 71 \mathrm{H}$ yeast cells (Invitrogen, Carlsbad, CA).

The tmfA, cryllAa-tmfA and gst-cryllAa-tmfA sequences were optimized using Pichia codons (www.kazusa.or.jp) (Fig. 2c). Ae. aegypti tmfA was synthesized by Gemini Biotech (Gainesville, FL) and cloned directly into pPICZB, and the combined genes cryl1Aa-tmfA and gst-cryllAa-tmfA were synthesized by GenScript (Piscataway, NJ). The synthetic genes were cut with $X h o \mathrm{I}$ and $\mathrm{Xba \textrm {I }}$, cloned into pUC57 and subsequently ligated into pPICZB XhoI and XbaI sites (Fig. 2a and b). The cloned genes were sequenced (Applied Biosystems, Foster City, CA) and analyzed at the University of Florida Biotech Center (http://www.biotech.ufl.edu/about.html). Plasmids carrying full length genes without mutations were used.

E. coli $\mathrm{INV} \alpha \mathrm{F}$ cells (Invitrogen, Carlsbad, CA) were transformed and clones were selected in the presence of 25 $\mu \mathrm{g} \mathrm{ml}{ }^{-1}$ zeocin (Invitrogen, Carlsbad, CA). Positive clones were grown in LB medium in the presence of zeocin, and plasmids were harvested, purified using Qiagen plasmid miniprep kit and screened by PCR. Positive plasmids with inserts were linearized with $S a c I$ and used to transform $P$. pastoris KM71H with Easy Comp kit (Invitrogen, Carlsbad, CA). The transformed cells were spread on YPD plates containing sorbitol $(1 \mathrm{M})$ and zeocin $\left(100 \mu \mathrm{g} \mathrm{ml}^{-1}\right)$. Positive colonies were screened for zeocin resistance (100 to 3,000 $\left.\mu \mathrm{g} \mathrm{ml}^{-1}\right)$. Cells that showed high resistance to zeocin (2-3 mg $\mathrm{ml}^{-1}$; harboring 10 to 20 inserts) and grew slowly in the presence of methanol $\left(\mathrm{Mut}^{\mathrm{s}}\right)$ were selected. The cells were stored at $-80^{\circ} \mathrm{C}$ in glycerol until used. For protein studies, single colonies were isolated from YPD plates containing zeocin and grown in minimal glycerol medium (1\%)
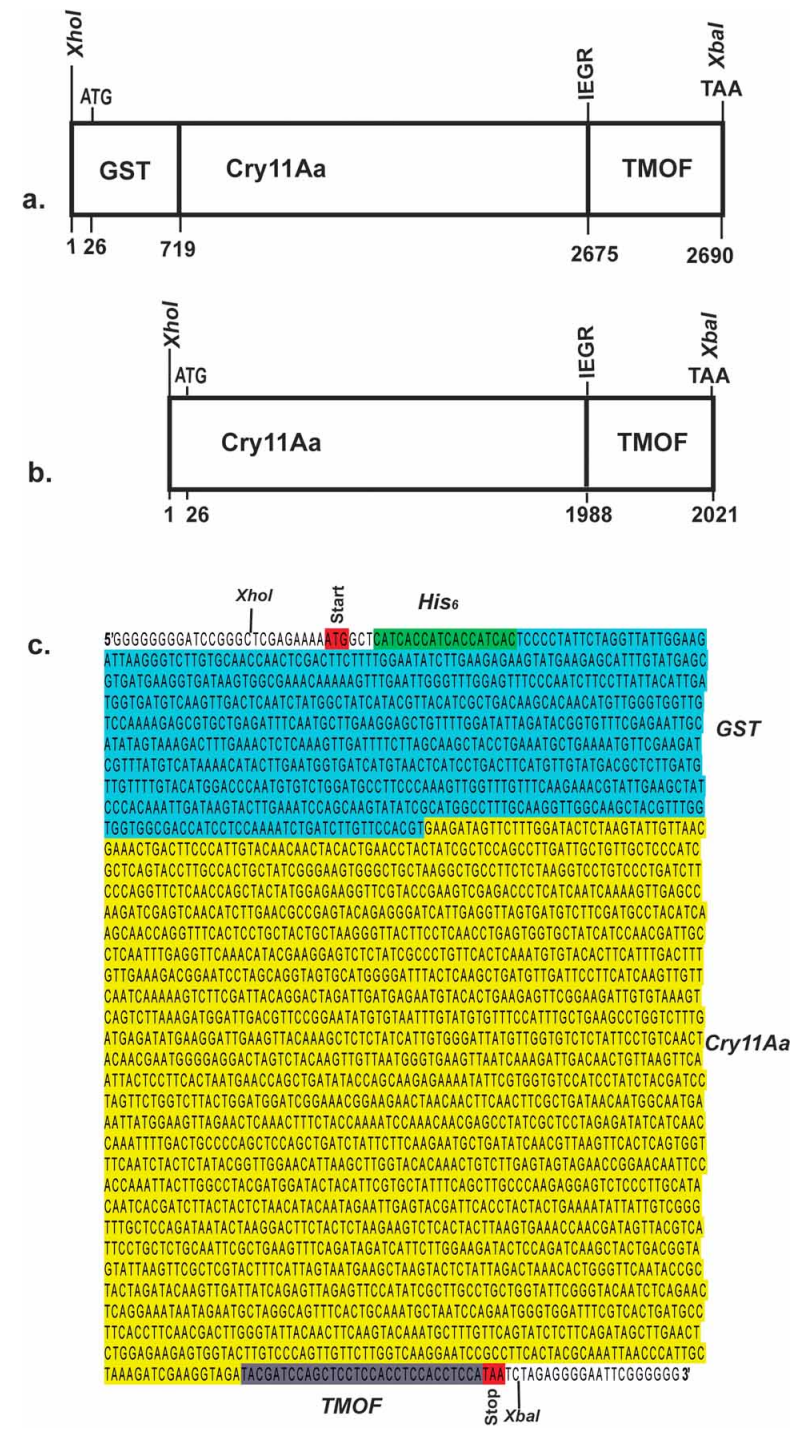

Fig. (2). Genomic organization of cryl1Aa-tmf synthetic gene. a. gst-cry11Aa-tmfA (2,690 nt) genetic map with restriction enzymes cleavage sites for cloning, the ATG start signal, the IEGR trypsin cleavage site and the TAA stop signal. b. cryl1Aa-tmfA (2,021 nt) genetic map with restriction enzymes cleavage sites for cloning, IEGR trypsin cleavage site and start (ATG) and stop (TAA) signals. c. gst-cryl1Aa-tmf optimized synthetic gene sequence: His $\sigma_{6}$ gst (green-blue), cry11Aa (yellow) and tmfA (grey), with the stop and start signals (red).

containing yeast nitrogen base in the presence of zeocin (both at $100 \mu \mathrm{g} \mathrm{ml}^{-1}$ ) at $30^{\circ} \mathrm{C}$ in a shaking $(250 \mathrm{rpm}$ ) incubator for 2-3 days. The cells were then centrifuged, and after supernatant removal induced with a fresh minimal medium (yeast nitrogen base with ammonium sulfate without amino acids) containing biotin and zeocin $\left(100 \mu \mathrm{g} \mathrm{ml}^{-1}\right)$ in the presence of $0.5 \%$ methanol for 24-96 hours.

\section{Protein Purification and Mass Spectrometry}

Yeast cells were collected by centrifugation, broken with Y-PER (Pierce, Rockford, IL) or with 8 M Urea and glass beads in a DNA FastPrep (BIO 101, Inc., Vista, CA), centrifuged and stored frozen at $-20^{\circ} \mathrm{C}$ until use. The extracted proteins were adsorbed onto Ni-nitrilotriacetic acid (Ni-NTA) agarose column (Qiagen, Valencia, CA), washed with phos- 
phate buffer $\mathrm{pH} 8.0$, and eluted with $20 \mathrm{mM}$ and $250 \mathrm{mM}$ imidazole. Samples from the eluted peaks were removed, dried by Speed Vac, rehydrated in 3\% SDS and 5\% $\beta$ meracptoethanol, $50 \mathrm{mM}$ Tris $\mathrm{pH} 8.8$, heated for $5 \mathrm{~min}$ at $95^{\circ} \mathrm{C}$ and analyzed by $10 \%$ SDS PAGE [25]. The gels were fixed and stained with coomassie brilliant blue and bands that migrated at the same molecular weight of the recombinant proteins were cut, digested with trypsin and analyzed by mass spectrometry (http://www.biotech.ufl.edu/about.html).

\section{Bioassays for Larvicidal Activity}

Recombinant $E$. coli were grown at $37^{\circ} \mathrm{C}$ in $\mathrm{LB}$ medium, induced with IPTG and harvested after $4 \mathrm{~h}$ [26]. Recombinant Anabaena were grown at $30^{\circ} \mathrm{C}$ in $\mathrm{BG} 11$ medium containing $25 \mu_{\mathrm{g} \mathrm{ml}}{ }^{-1}$ neomycin in $250 \mathrm{ml}$ flasks for 12 days, as previously described [19]. Bti and P. pastoris cells were grown in the appropriate liquid media and the latter induced with methanol $(0.5 \%)$. Yeast recombinant cells were collected by centrifugation, washed and resuspended in distilled water, and used without or with heat inactivation at $50^{\circ} \mathrm{C}$ for $3 \mathrm{~h}$.

Autoclaved brewer's yeast and heat inactivated $\left(75^{\circ} \mathrm{C}\right.$ or $50^{\circ} \mathrm{C}$ for $3 \mathrm{~h}$ ) Pichia cells without tmfA were used as controls. Recombinant cells producing TMOF, GSTCry11Aa-TMOF or Cry11Aa-TMOF were washed 3-times in sterile distilled water and added to 48 well plates, each containing a single $1^{\text {st }}$-instar Ae. aegypti larva in $1 \mathrm{ml}$ sterile water. For large scale feedings, 20 such larvae were added into glass dishes containing $160 \mathrm{ml}$ sterile water and different concentrations of toxins (Cry4Aa, Cry11Aa, Cyt1Aa and P20) produced in E. coli [27] or TMOF produced in $P$. pastoris [28]. Each bioassay was independently performed in triplicates. Mortality was followed for 12 days at $28^{\circ} \mathrm{C}$. Values of $\mathrm{LC}_{50}$ and $\mathrm{LC}_{90}$ (concentration of cells that kill $50 \%$ and $90 \%$ of the exposed populations, respectively) were determined using probit analysis (EPA Probit analysis program) for 6-12 doses.

\section{ELISA (Enzyme Linked Immunoadsorbant Assay)}

Recombinant bacteria were dried in a Speed Vac or lyophilized. TMOF-producing $P$. pastoris $\mathrm{KM} 71 \mathrm{H}$ cells were grown in $4 \mathrm{~L}$ flasks and stimulated for $120 \mathrm{~h}$ with $0.5 \%$ methanol. Cells were washed with sterile water to remove medium and external proteins, and collected by centrifugation. To the washed cells $400 \mu \mathrm{l}$ of Y-PER (Pierce, Rockford, IL) was added and the cultures were gently shaken for $20 \mathrm{~min}$ at room temperature. The cells were disrupted by ultrasonic disintegration or with glass beads by shaking for $40 \mathrm{sec}$ at speed 6 with Lysing Matrix C in a DNA Fast Prep Instrument (BIO 101, Vista, CA).

The amounts of TMOF in samples were determined by ELISA [29]. Briefly, to each well of reacti-bind maleic anhydride activated polystyrene plates (Pierce, Rockford, IL) 100 $\mu \mathrm{l}$ of PBS buffer (0.1 M Phosphate, $0.15 \mathrm{M} \mathrm{NaCl}, \mathrm{pH} 7.2$ ) and TMOF of known concentrations (10 $\mathrm{ng}$ to $1.2 \mathrm{mg}$ in 10 $\mu$ ( PBS), pH 7.2 were added to construct a calibration curve. Similarly, proteins that were extracted from recombinant cells were also tested. The maleic anhydride well plates were incubated by gentle shaking at room temperature for $1 \mathrm{~h}$ and at $4^{\circ} \mathrm{C}$ overnight without shaking. The solutions were then decanted from the wells, and to each well $300 \mu \mathrm{l}$ of a blocking solution TTBS (50 mM Tris- $\mathrm{HCl}, 0.15 \mathrm{M} \mathrm{NaCl}, 0.05 \%$ Tween 20, 3\% BSA, pH 7.2) was added and incubated for 1 h. The solutions were then decanted from the wells, and to each well $100 \mu \mathrm{l}$ of TMOF antiserum that was diluted 1:100 in $0.05 \%$ Tween-20, PBS, $0.1 \%$ BSA (dilution buffer) was added and incubated for $1 \mathrm{~h}$. The wells were washed 3-times with TTBS by gentle shaking for 5 minutes each. To each well $100 \mu \mathrm{l}$ of Goat anti-rabbit antibody linked to alkaline phosphatase diluted in a dilution buffer $(1: 15,000)$ was added, and incubated for $1 \mathrm{~h}$. The wells were washed 3-times with TTBS and to each well $200 \mu \mathrm{l}$ of alkaline phosphatase liquid substrate (Sigma, St. Louis, MS) was added and incubated for 30-60 min until a yellow color developed and the absorbance was read at $405 \mathrm{~nm}$ in an ELISA plate reader Model EL 308 (Bio-Tek Instruments, Burlington, Vermont).

The absorbency at $405 \mathrm{~nm}$ was plotted against the log concentration (ng) of the TMOF standard to construct a calibration curve. The amount of TMOF in the tested recombinant cells was read directly from the linear part of the calibration curve.

\section{HPLC (High Pressure Liquid Chromatography)}

Recombinant Anabaena cells were grown, harvested, lyophilized, washed and sonicated. The broken cells were centrifuged and the supernatants collected and acidified with $50 \mu \mathrm{l}$ TFA (trifluoroacetic acid). The acidified solution was vortexed and centrifuged at $14,000 \mathrm{rpm}$ for $5 \mathrm{~min}$. Supernatants were adsorbed onto Sep-Pak $\mathrm{C}_{18}$ reversed-phase cartridges (Millipore, Milford, Mass), the column washed with 4 $\mathrm{ml}$ water, $0.1 \%$ TFA and TMOF was eluted with $100 \%$ acetonitrile, $0.1 \%$ TFA ( $4 \mathrm{ml}$ ), dried by Speed Vac at $40^{\circ} \mathrm{C}$, and taken up in $100 \mu \mathrm{l}$ water. To the rehydrated samples (90 $\mu 1)$, TFA $(10 \mu \mathrm{l})$ was added and the samples chromatographed by a high-performance liquid chromatography (HPLC) system with a Microsorb $5 \mu \mathrm{m} \mathrm{C}_{18}$ reversed-phase column $(4.6 \mathrm{~mm}$ ID by $25 \mathrm{~cm})$, a $5-\mu \mathrm{m}$ guard cartridge, and a gradient of acetonitrile $(0-100 \%)$ in $0.1 \%$ TFA. Absorbance was followed at $220 \mathrm{~nm}$ at 1 absorbance unit at full scale (AUFS). Fractions $(1 \mathrm{ml})$ were collected, dried by Speed Vac and rehydrated in $100 \mu \mathrm{l}$ PBS. Samples were analyzed by ELISA for the presence of TMOF using reactibind maleic anhydride activated polystyrene plates (Pierce, Rockford, IL).

\section{RESULTS}

\section{Cloning and Expression of tmfA in Anabaena}

TMOF-coding region (bases 25-54, underlined; tmfA) was optimized using Anabaena PCC 7120 codons. The sequence of 12 bases coding for a trypsin cleavage site (IEGR) was introduced upstream (bases 13-24), to release in the larval midgut free TMOF that inhibits trypsin biosynthesis: 
To construct pBVE4-TE (Fig. 1), two overlapping oligonucleotides of 41 (NcoI) and 38 (PstI) bases with overlap of 12 nucleotides were synthesized, annealed and amplified by PCR:

\section{Bti $\delta$-Endotoxins and TMOF}

It is anticipated that starved mosquito larvae are more sensitive to $\delta$-endotoxins than well nourished larvae because they are weaker, swim slower in water and may consume

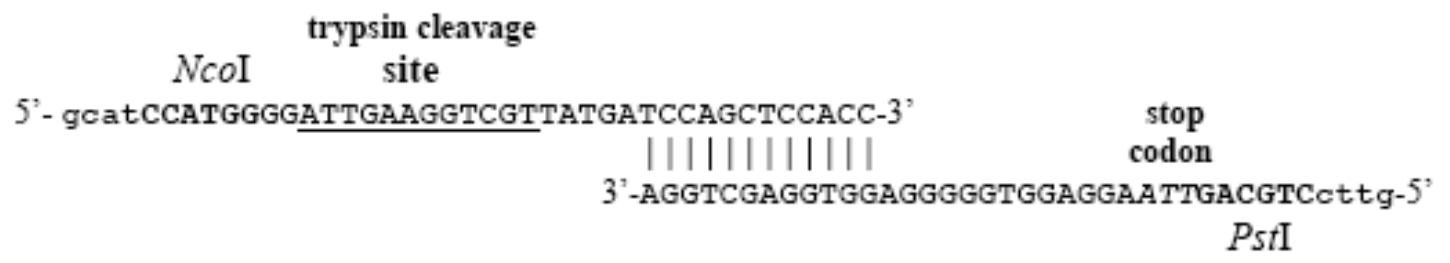

The 67 bp NcoI-PstI amplicon was purified by PAGE, cut and ligated into $\mathrm{pBS}-\mathrm{SK} / \mathrm{N}$ at the NcoI-PstI site upstream $P_{A l}$ [18], and the resultant pBVE4-TE was transformed into E. coli XL1-Blue MRF'. pBVE4-TE was cut with $K p n I / S a c I$ and the $P_{A 1}$-tmfA fragment ligated into pRL488p, containing $P_{p s b A}$ downstream of the KpnI-SacI site, yielding pRVE4-TE (Fig. 1). The recombinant plasmid was transformed into and amplified in E. coli XL1-Blue MRF'. The plasmid with the dual promoters $P_{p s b A}$ and $P_{A I}$ was introduced into Anabaena PCC 7120 by biparental conjugation [24].

Another sequence encoding TMOF without IEGR was also designed for expression in E. coli and in Anabaena PCC 7120:

$$
\begin{gathered}
\text { Y } \\
\text { 5 } \\
\text { 5 -TATGATCCAGCTCCACCTCCCCCACCTCCTTAACTGCAGgaac-3, } \\
\text { | } \\
\text { 3 }
\end{gathered}
$$

Two oligonucleotides, 43 bases each, were synthesized and annealed and the gene was ligated into the PstI/NcoI cloning site of pBS-SK/N ( NcoI site of the vector was filledin by Klenow fragment), yielding pBVE4-T that was transformed into E. coli XL1-Blue MRF'. pBVE4-TE and pBVE4-T were digested with $K p n I / S a c I$ and the $P_{A I}$-tmfA fragments ligated into pRL488p, containing $P_{p s b A}$ downstream the KpnI-SacI site, yielding pRVE4-TE and pRVE4-T, respectively (Fig. 1). The recombinant plasmids were transformed and amplified in E. coli XL1-Blue MRF'. The plasmids with the dual promoters $P_{p s b A}$ and $P_{A I}$ were introduced into Anabaena PCC 7120 through DH10B (carrying conjugal and helper plasmids) by biparental conjugation [24].

To find out the expression level of tmfA alone (without $B t i$ toxin genes) in Anabaena, it was fused in frame to the Cterminal segment of $p 20$ (encoding an accessory, non toxic $B t i$ protein) and the gene was expressed with and without a protease cleavage site (IEGR). Recombinant cells were grown, and protein extracted and analyzed by HPLC and ELISA for TMOF. Transgenic clones of Anabaena PCC 7120 synthesized $0.5-1 \mu \mathrm{g}$ of TMOF in $10^{8}$ cells, higher than in $E$. coli (35-650 ng in $10^{8}-10^{9}$ cells). However, when tmfA was expressed in Bti the synthesis of the hormone was even lower (67-267 ng in $10^{8}-10^{9}$ cells). These results indicate that the expression level of tmfA in Anabaena, E. coli and Bti is low. Perhaps the decapeptide precipitates in inclusion bodies or it needs to be fused to a larger protein in order to efficiently be synthesized in bacteria. more toxin than non starved larvae (Borovsky, unpublished observations). Indeed, $1^{\text {st }}$ instar larvae starved from emergence were 35 -fold more sensitive than well nourished larvae fed with Brewer's yeast $\left(80 \mathrm{mg} \mathrm{ml}^{-1}\right)$, whereas $3^{\text {rd }}$ instar larvae that were starved of Brewer's yeast for a day were only 6-fold more sensitive to $\delta$-endotoxins than well nourished larvae (Table 1).

Table 1. Toxicity of Bti Against Ae.aegypti Larvae

\begin{tabular}{|c|c|c|}
\hline \multirow{2}{*}{ Larval Instar } & \multicolumn{2}{|c|}{$\mathbf{L C}_{\mathbf{5 0}}\left(\mathrm{ng} \mathrm{m}^{\mathbf{1}}\right)$} \\
\cline { 2 - 3 } & Starved & Fed \\
\hline \hline First & 1.6 & 55.6 \\
\hline Third & 17.7 & 105.5 \\
\hline
\end{tabular}

Aedes aegypti larvae (2 groups of 20 larvae per group) were fed a dry preparation of $B$. thurengiensis subsp. israelensis $\delta$-endotoxins and mortality was determined after $24 \mathrm{~h}$. Results are average of 2 determinations with no more than $5-10 \%$ differences between groups.

These results encouraged us to express a synthetic tmf A in $P$. pastoris $\mathrm{KM} 71 \mathrm{H}$. The yeast cells were heat inactivated $\left(50^{\circ} \mathrm{C}\right.$ for $\left.3 \mathrm{~h}\right)$ and 3 different concentrations of the hormone were fed together with $10^{5} \mathrm{E}$. coli cells expressing cry $4 \mathrm{Aa}$, cryl1Aa, cyt $1 A a$ and $p 20$ [27], to groups of twenty $1^{\text {st }}$ instar Ae. aegypti larvae, and larval survival was monitored daily for 6 days (Table 2). All the larvae that were fed by the transgenic $E$. coli alone died, but none died upon addition of $P$. pastoris cells transformed with empty pPICZB, as in the control. Thus, $P$. pastoris not only serves as a good food source for the larvae-it protects them from the Bti toxins as well. Feeding recombinant $P$. pastoris cells with high TMOF concentration alone $(298 \mathrm{nM})$ did not cause appreciable larval mortality in 6 days. After 12 days of feeding, however, $90 \%$ of the larvae died from starvation and lack of trypsin biosynthesis (data not shown). Lower TMOF concentrations $(75 \mathrm{nM})$ in the transgenic $P$. pastoris cells restored the toxicity of the $\delta$-endotoxins produced by E. coli $\left(10^{5}\right.$ cells $)$; mortality reached $95 \%$ after 6 days of feeding (Table 2). Feeding E. coli expressing Bti toxin genes in the presence of $P$. pastoris cells or $P$. pastoris expressing tmfA alone did not affect mosquito larvae (Table 2). These results indicate that TMOF enhances the effect of Bti toxins in organic rich environments that are abundant in nature. 
Table 2. Feeding of Recombinant E. coli (pVE4-ADRC) and P. pastoris-tmfA to Ae. aegypti Larvae

\begin{tabular}{|c|c|c|c|}
\hline Larvae fed with: & TMOF (nM) & $\begin{array}{c}\text { E. coli } \\
\left(\text { cells } \mathrm{ml}^{-1}\right)\end{array}$ & Surviving larvae \pm S.E.M. \\
\hline Pichia (control) & 0 & 0 & $16.7 \pm 0.3^{\mathrm{a}, \mathrm{c}}$ \\
\hline E. coli (pVE4-ADRC) & 0 & $10^{5}$ & $0 \pm 0^{\mathrm{a}, \mathrm{d}}$ \\
\hline Pichia + E. coli (pVE4-ADRC) & 0 & $10^{5}$ & $17 \pm 0.6^{\mathrm{c}}$ \\
\hline Pichia -tmfA + E. coli (pVE4-ADRC) & 298 & $10^{5}$ & $0.7 \pm 0.7^{\mathrm{a}, \mathrm{b}, \mathrm{d}}$ \\
\hline Pichia -tmfA + E. coli (pVE4-ADRC) & 149 & $10^{5}$ & $1.3 \pm 0.7^{\mathrm{a}, \mathrm{b}}$ \\
\hline Pichia - tmfA + E. coli (pVE4-ADRC) & 75 & $10^{5}$ & $1.3 \pm 0.9^{\mathrm{a}, \mathrm{b}}$ \\
\hline Pichia $-t m f A$ & 298 & 0 & $18.7 \pm 0.7^{\mathrm{c}, \mathrm{e}}$ \\
\hline
\end{tabular}

E. coli cells transformed with pVE4-ADRC expressing cry4Aa, cryl1Aa, cytlAa and p20 [27] were fed for 6 days to 3 groups of $1^{\text {st }}$ instar larval Ae.aegypti (20 larvae per group in $160 \mathrm{ml}$ water) in the presence of different concentrations of recombinant $P$. pastoris cells expressing TMOF that were heat inactivated at $75^{\circ} \mathrm{C}$ for $3 \mathrm{~h}$. Larval survival was followed in triplicates and is expressed as mean \pm S.E.M. The amount of TMOF in recombinant $P$. pastoris cells was determined by ELISA.

${ }^{a}$ Significant difference from control by student's $t$-test $p<0.008$,

b,c,d not significant difference $p<0.6$,

${ }^{\text {e}}$ Pichia-tmfA (75-298 nM) kill $90 \%$ of mosquito larvae in 12 days

\section{Larvicidal Activities of Recombinant $P$. pastoris Cells and Cell-Free Proteins}

\section{a. Cry11Aa-TMOF}

KM71H Cells of $P$. pastoris-cry11Aa-tmfA were grown for $96 \mathrm{~h}$ in the presence of $0.5 \%$ methanol. At $24 \mathrm{~h}$ intervals, the cells were harvested, washed and aliquots $\left(10^{8}\right.$ cells $)$ were fed to individual Ae. aegypti larvae in 48 well-plates. Cells that were induced for 24 and $48 \mathrm{~h}$ killed few larvae at 5-6 days and $82 \%$ at day 12 (Fig. 3). A longer induction period of $96 \mathrm{~h}$ caused rapid mortality; $63 \%$ of the larvae died within 2 days. Only $12.5 \%$ of the larvae died when fed $P$. pastoris cells transformed with an empty pPICZB plasmid (control) or brewer's yeast cells (Fig. 3). These results are consistent with the conclusion that TMOF enhances the activity of $B t i$ toxins (Table 2).

\section{b. GST-Cry11Aa-TMOF}

To find out if some of the newly synthesized Cry11AaTMOF precipitated in the cytoplasm or was shunted to the peroxisome and thus was less toxic to the larvae, we synthesized a glutathione-S-transferase (GST) synthetic gene and fused it in frame to cryllAa-tmfA yielding gst-cryllAatmfA with 10-20 copies per cell. Ae. aegypti larvae that fed on these cells, induced with methanol, died faster than larvae that fed on cells producing Cry11Aa-TMOF (compare Fig. 3 with Fig. 4). At day 5, 88\%,75\% and $73 \%$ of the larvae died after eating cells that were induced for $96 \mathrm{~h}, 72 \mathrm{~h}$ and $48 \mathrm{~h}$,

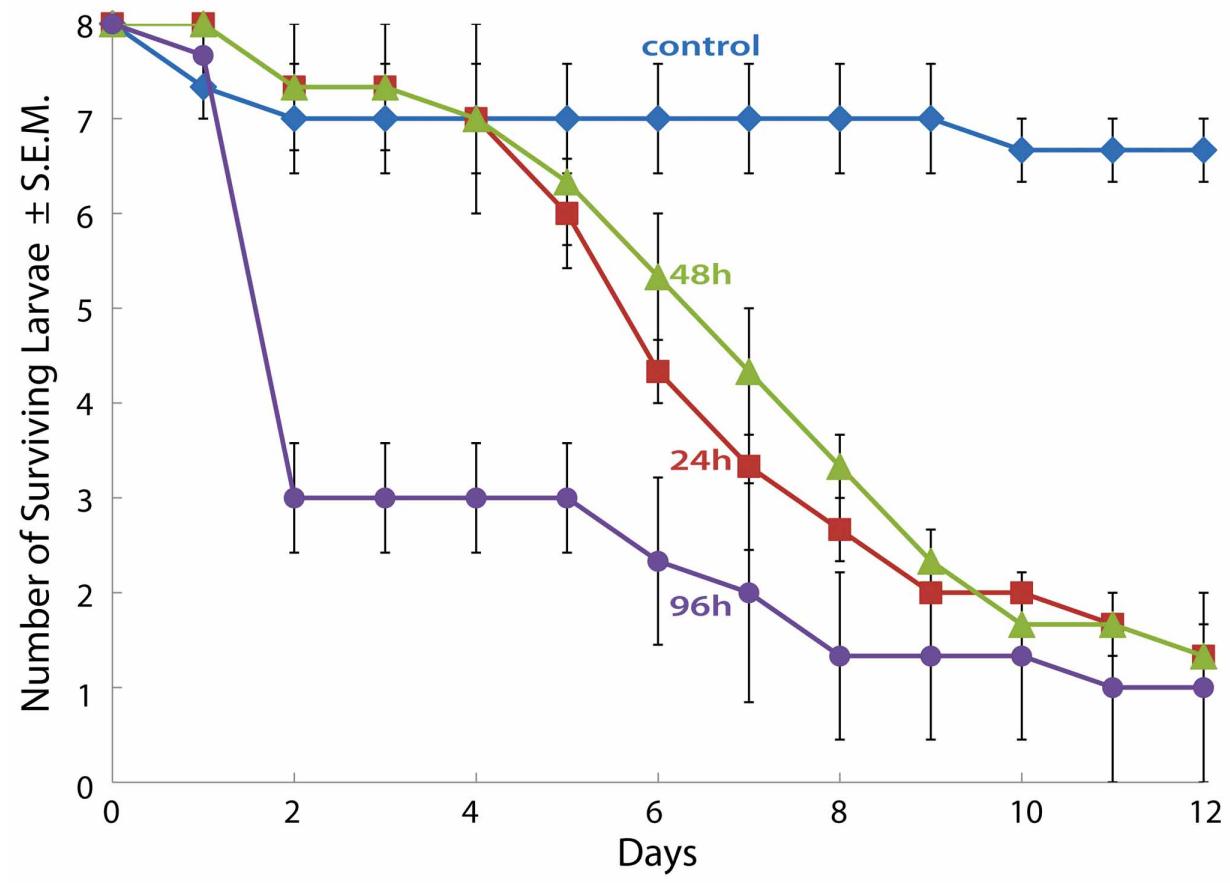

Fig. (3). Feeding P. pastors-cryl1Aa-tmfA cells to Ae. aegypti larvae. P. pastoris cells expressing cryl1Aa-tmfA were fermented for 24 , 48 and $96 \mathrm{~h}$ in the presence of methanol $(0.5 \%)$. Three groups of eight $1^{\text {st }}$ instar larvae were fed for 12 days $10^{8}$ cells/larva in 48 well-plates. Larval survival was followed daily. Results are expressed as means of 3 determination \pm S.E.M. Controls were fed $P$. pastoris cells without cryl1Aa-tmfA. 


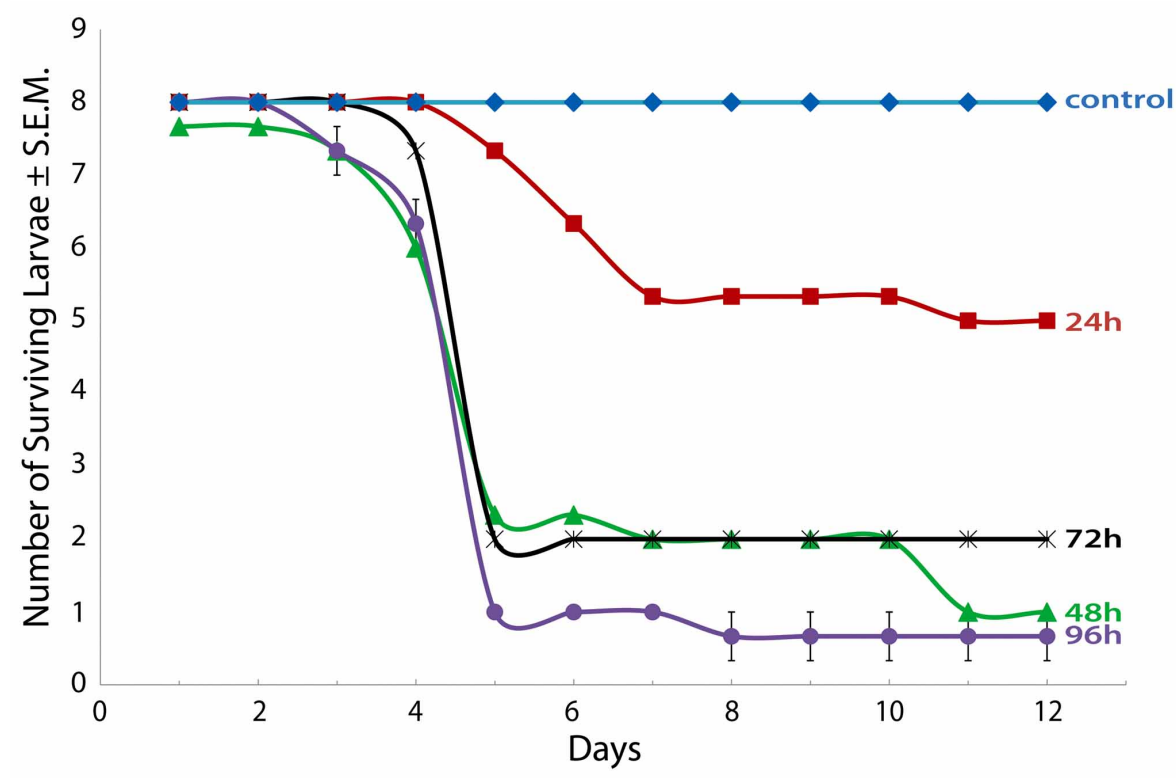

Fig. (4). Feeding P. pastoris-gst-cryl 1Aa-tmfA to Ae. aegypti larvae. Cells were fermented in the presence of methanol and fed to Ae. aegypti larvae as in Fig. (3). Survival was recorded daily, and results are expressed as means of 3 determinations \pm S.E.M. Controls were fed $P$. pastoris cells without gst-cry11Aa-tmfA. No effect was found when Pichia-gst cells were fed to larvae (results not shown).

respectively (Fig. 4). Cells that were induced for $24 \mathrm{~h}$ were not as effective; $12.5 \%$ of the larvae died at day 5 and $37.5 \%$ at day 12 (Fig. 4), whereas cells expressing gst alone did not kill larvae (data not shown). These results indicate that fusing GST to Cry11Aa-TMOF enhances its solubility in the cytoplasm and its larvicidal activity.

\section{c. Cell-Free Extracted Proteins}

Early $4^{\text {th }}$ instar Ae. aegypti larvae were fed protein extract $(5.69 \mu \mathrm{g})$ isolated from $P$. pastoris cells that were transformed with gst-cryl1Aa-tmfA. After $24 \mathrm{~h}$ of feeding, $40 \%$ of the larvae died. Mortality in a control group that were fed non-transformed $P$. pastoris extract was 6.5-fold lower (Table 3). These results indicate that the transformed $P$. pastoris cells synthesize soluble GST-Cry11Aa-TMOF in the cell cytoplasm that is toxic to Ae. aegypti early $4^{\text {th }}$ instar larvae.

\section{d. Heat Stability of GST-Cry11Aa-TMOF}

Exposure of gst-cryllAa-tmfA-expressing P. pastoris cells to $50^{\circ} \mathrm{C}$ for $3 \mathrm{~h}$ increased $\mathrm{LT}_{50}$ and $\mathrm{LT}_{90}$ (time required to kill 50 and $90 \%$ of the larval population) by 1.2 and 3.7 days respectively, as compared with untreated proteins (Table 4). These results indicate that for future field testing, it is possible to heat inactivate our recombinant yeast cells synthesizing GST-Cry11Aa-TMOF with little effect on the toxicity of the cells towards mosquito larvae.

\section{Purification and Mass Spectrometry Analysis of Cry11Aa}

To find out whether the biological activity of the recombinant $P$. pastoris cells is due to Cry11Aa-TMOF, $P$. pastoris cells (AOX1:cry11Aa-tmfA) were induced for $96 \mathrm{~h}$ and broken with Y-PER and glass beads, followed by extraction with $8 \mathrm{M}$ urea, and the combined cell extract was purified by Ni-NTA column chromatography. A protein peak $(235 \mu \mathrm{g})$ eluted at $250 \mathrm{mM}$ imidazole was collected and analyzed by PAGE SDS [25]. After electrophoresis, the gel was stained, a band at $M_{r} 72 \mathrm{kDa}$ isolated and analyzed by mass spectrometry (Fig. 5). Nine unique peptides at different locations on the protein were found that cover $14 \%$ of the entire protein identifying Cry11Aa with $95 \%$ confidence.

\section{DISCUSSION}

Insect resistance to insecticides poses a serious agricultural and public health problem. Resistance has been reported against Bti in field populations of Culex pipiens [30] and in laboratory populations of Cx. quinquefasciatus [31]. Co-expressing several toxin genes having different modes of action might enhance toxicity and delay or prevent resistance. Since TMOF and $\delta$-endotoxins kill mosquito larvae in different mechanisms, it is possible that they are synergistic, just as $\delta$-endotoxins from other $B t$ subsps and bacterial endochitinase against $S$. littoralis $[21,22]$ and $A e$. aegypti larvae [23].

TMOF inhibits the biosynthesis of trypsin [2], which activates $\delta$-endotoxins in the larval midgut. If both, $\delta$ endotoxins and TMOF are fed together to mosquito larvae in recombinant cells expressing their genes, inhibition of trypsin biosynthesis by TMOF may interfere with the activation of the $\delta$-endotoxins. Therefore, genes encoding the active portion of these polypeptides [32] should be used in concert with TMOF. Since larval killing by $\delta$-endotoxins is fast [12], whereas that of TMOF is slow and transmitted through signal transduction pathway, translational control and secondary messengers [2, 4, 7, 33-35]. The activation of the $\delta$-endotoxins may be accomplished by pre-existing endogenous larval gut trypsin before its level in the midgut is reduced by TMOF. In addition, larval starvation, which occurs later on, will slow down repair of sub-lethal damaged gut epithelium by $\delta$-endotoxins [36], enhancing gut absorption of TMOF into the hemolymph. Starved larvae may also eat more recombinant yeast cells bearing toxins thus enhancing larval demise. Toxicity of crylC against advanced larval stages $\left(3^{\text {rd }}\right.$ - and $5^{\text {th }}$-instars $)$ of $S$. littoralis is, indeed, reduced due to high levels of protease activity in the gut which 
Table 3. Feeding Larvae Cell Free Extract of P. pastoris Cells Expressing gst-cry11Aa-tmfA

\begin{tabular}{|lccc|}
\hline \multicolumn{1}{|c|}{ Cells Extract } & N & Dead larvae \pm S.E.M. & Mortality $(\%)$ \\
\hline \hline a. Pichia gst-cry11Aa-tmfA 96 h fermentation & 8 & $6.38 \pm 0.86$ & 40 \\
b. Pichia control & 4 & $1.0 \pm 0$ & 6 \\
\hline
\end{tabular}

P.pastoris cells were fermented for $96 \mathrm{~h}$ and the cells were broken with glass beads and Y-PER, the extract was centrifuged, the supernatant collected and aliquots of (5.69 $\mu \mathrm{g}$ ) fed to individual early $4^{\text {th }}$ instar Ae. aegypti larvae (16 larvae per group) in 48 well plates in $1.0 \mathrm{ml}$ water. Larval mortality was recorded $24 \mathrm{~h}$ later. Controls were fed protein extract from cells that were not transformed. The results are expressed as averages of 4 or 8 determinations \pm S.E.M.

Table 4. Feeding of Heat Treated and Untreated P. pastoris Cells Expressing gst-cry11Aa-tmf A

\begin{tabular}{|c|c|c|c|c|}
\hline $\begin{array}{l}\text { P. pastories } \mathrm{KM} 71 \mathrm{H} \\
\text { AOX1:gst-cry11Aa-tmfA } \\
\text { cells were induced for } 96 \mathrm{~h} \text { and fed to } \\
\text { mosquito larvae }\end{array}$ & $\begin{array}{c}\mathbf{L T}_{50} \\
(\text { days })\end{array}$ & $\begin{array}{c}\text { Confidence Limit }(95 \%) \\
\text { (days) }\end{array}$ & $\begin{array}{c}\mathbf{L T}_{90} \\
(\text { days })\end{array}$ & $\begin{array}{c}\text { Confidence Limit (95\%) } \\
\text { (days) }\end{array}$ \\
\hline a. Untreated & 4.62 & $3.655-5.477$ & 8.27 & $6.853-11.461$ \\
\hline $\begin{array}{l}\text { b. Heat inactivated at } \\
50^{\circ} \mathrm{C} \text { for } 3 \mathrm{~h}\end{array}$ & 5.88 & $4.822-6.896$ & 12.07 & $9.705-18.095$ \\
\hline
\end{tabular}

Cells were induced with methanol for $96 \mathrm{~h}$, and 3 groups of 8 larvae were fed individually in 48 well plates for 12 days. The recombinant cells were untreated or heat inactivated at $50^{\circ} \mathrm{C}$ for $3 \mathrm{~h}$. The mortality of each group was recorded at $24 \mathrm{~h}$ intervals for 12 days, and the results were subjected to probit analysis. Each experiment was repeated 3 times. $\mathrm{LT}_{50}=$ Lethal time required to kill $50 \%$ of the larvae. $\mathrm{LT}_{90}=$ Lethal time required to kill $90 \%$ of the larvae.

rapidly degrades the ingested toxin [37]. The proteases that are responsible for the inactivation of Cry $1 \mathrm{C}$ are inhibited by trypsin-specific inhibitor such as PMSF. Thus, lowering the level of trypsin-like enzymes in the larval gut by TMOF might protect extensive degradation and inactivation of Bti toxins. Synergy is thus anticipated between TMOF and Bti enhancing larval killing at lower $\delta$-endotoxin concentrations. Thus, constructing genes encoding chimeric proteins that use trypsin to release TMOF and simultaneously activate the $\delta$ endotoxins is an advantage, and our report confirms this hypothesis.

We report here that starved Ae. aegypti larvae are 6-35 fold more sensitive to Bti toxins than well-fed larvae (Table 1), and starved $1^{\text {st }}$ instar larvae are 10 -fold more sensitive than $3^{\text {rd }}$ instars. Since TMOF is more effective against $1^{\text {st }}$ and $2^{\text {nd }}$ instar larvae [9], the use of both toxins in early developmental stages is expected to enhance the effect of low toxin doses and reduce the amount of Bti required in sewage treatment ponds in which it is not effective alone.

The high toxicity of recombinant $E$. coli expressing cry $4 A a$, cryl1Aa and cyt1Aa [27] to $1^{\text {st }}$ instar Ae. aegypti larvae was dramatically reduced in the presence of $P$. pastoris as a nutritious food source (Table 2). Mortality was restored (about 95\%) upon replacing it with recombinant $P$. pastoris producing TMOF (75-249 nM), which was not toxic alone (Table 2). These results confirm our hypothesis that TMOF and Bti are synergisitic against larvae of Ae. aegypti in organic rich environment. TMOF enhances the toxicity of $\delta$-endotoxins by inhibiting trypsin biosynthesis, causing anorexia, starvation and death. These results confirm earlier observation that ingested nutritious particles reduce the susceptibility of insect larvae to $\delta$-endotoxins [38], indicating that other mechanisms (e.g. blocking of toxins receptor sites) may also play an important role. This observation explains why $B t i$ is not effective against mosquito larvae in sewage treatment ponds. TMOF, on the other hand, traverses the gut epithelial cells and binds to its gut receptors at the hemolymph side $[6,7,34,35]$. Since TMOF and Bti have different mechanisms of action, increased resistance in exposed mosquito population against their combination is not likely. Although Bti and TMOF act like synergists in the laboratory, they must be tested under stringent field conditions for future larval control applications.

When cry4Aa-tmfA was cloned and expressed in $P$. pastoris KM71 cells without codon-optimization [28], the activity of the construct was poor. Codon optimized chimeric cryl1Aa-tmfA and gst-cryl1Aa-tmfA (Fig. 2) expressed in $P$. pastoris cells was effective against Ae. aegypti larvae (Figs. 3 and 4). Fusing GST and SUMO (small ubiquitin-related modifier) to proteins enhances their activity in bacteria and yeasts by increasing solubility in the cytoplasm [39]. Indeed, GST enhanced the heat stability of Cry11Aa-TMOF (Table 4), allowing heat inactivation of the yeast cells in future field applications without endangering the environment.

The GST-Cry11Aa recombinant protein produced in Saccharomyses cerevisiae without using codon optimized gst-cryl1Aa was purified by affinity chormatogarphy on glutathione Sepharose column [40]; the purified protein and the cell free crude extract were biologically active against $3^{\text {rd }}$ instar Ae. aegypti larvae, but it was not reported whether the intact cells were also active. The cell free extract $(5.69 \mu \mathrm{g})$ of our $P$. pastoris clone expressing the chimeric gstcryl1Aa-tmfA was also biologically active, killing $40 \%$ of the early $4^{\text {th }}$ instar Ae. aegypti larvae in 24 h (Table 3 ).

Ogunjimi et al. [41] cloned and expressed cry2 in $P$. pastoris using $\mathrm{pPICZ} \alpha \mathrm{B}$ but did not report if the secreted protein was biologically active. A recombinant protein of 70 kDa was identified by SDS PAGE, but no mass spectrometry or $\mathrm{N}$ terminus analyses were reported that identified the putative protein as Cry2. Mass spectrometry analysis of Cry11Aa-TMOF that was purified from $P$. pastoris identified Cry11Aa but not TMOF that is fused to it with a trypsin cleavage site (IEGR) (Figs. 2 and 5). PCR-analysis of the recombinant cell DNA prior to the fermentation found a 


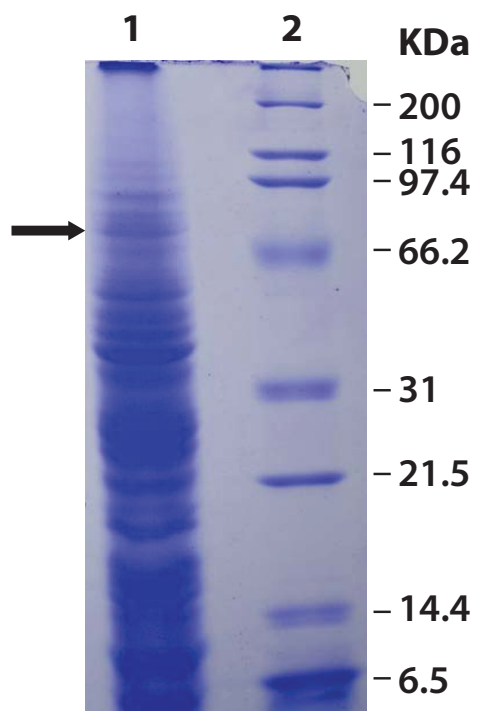

MEDSSIDTLS IVNETDELY NNYTEPTIAP ALIAVAPIAO YLATAIGKWA AKAAESKVLS LIEPGSOPAT MEKVRTEVET LLNOKLSODR VNILNAEYRG IIEVSDVEDA YIKOPGETPA TAKGYELNLS GAIIQRLPOE EVQTYEGVSI ALETOMCTLH LTLIKDGILA GSAWGETOAD VDSEIKLENO KVIDYRTRLM RMYTEEFGL CKVSLKDGLT ERNMCNLYVE PEAEATSLMR YEGLKLOSSL SLWDYGGSI PVNYNEWGGL VYKLIMGEVN QRLTTVRENY SETNEPADIP ARENIRGVHP IYDPSSGLTG WIGNGRTNN NEADNIGNE MEVRTOTEYO NPNEPIAPR DIINOILTAP APADLERKNA DINVKETOWE OSTLYGWIIK LGTOTVLSSR TGTIPPNYLA YDGYYIRAIS ACPRGVSLAY NHDLTTLTYN RIEYDSPTTE NIIVGEAPDN TKDEYSKKSH YLSETNDSYV IPALOEAEVS DRSELEDTPD OATDGSIKEA RTEISNEAKY SIRLNTGENT ATRYKLIIRV RVPYRLPAGI RVOSONSGNN RMLGSETANA NPEWVDEVTD AFTENDLGIT TSSTNALES SSDSLNGEE WYLSOLELVR ESAETTOINP LLK

Fig. (5). SDS-PAGE of Ni-NTA eluted proteins and mass spectra identification of Cry11Aa. P. pastoris cryl1Aa-tmfA cells were fermented in the presence of methanol $(0.5 \%)$ for $96 \mathrm{~h}$, cells extracted with Y-PER and $8 \mathrm{M}$ urea and proteins purified by affinity chromatography. Eluted proteins concentrated, separated by SDS-PAGE and stained with coomassie blue. A band at $\mathrm{M}_{\mathrm{r}} 72 \mathrm{kDa}$ (lane 1, arrow) was identified, cut and incubated with trypsin and the released peptides were assayed by mass spectrometry. Sequences that were identified by mass spectrometry are stained yellow, except for $\mathrm{M}$ which is stained green. Lane 2, molecular weight standards.

full length gene (cryllAa-tmfA). There are two ways to explain why TMOF was not detected by mass spectrometry: (a) the peptide was not cleaved in sufficient quantities during the tryptic digestion step, and (b) TMOF had been cleaved during the fermentation by yeast proteases releasing the hormone from the fusion protein into the cell cytoplasm. Because the $\mathrm{His}_{6}$ tag is fused to Cry $11 \mathrm{Aa}$, the cleaved TMOF lacks it and thus did not bind to the Ni-NTA column and could not be detected. Our recombinant proteins that are produced inside $P$. pastoris cells are protected by the yeast's cell wall from sunlight and bacterial degradation, and are more palatable to mosquito larvae [10].

Photosynthetic cyanobacterial species are excellent candidates for toxin delivery $[16,20]$. They are ubiquitous, float in the upper water layer and resist adverse environmental conditions. In addition, they are used as natural food sources for mosquito larvae $[42,43]$ and can be cultured on a large scale [44] and genetically altered [17-20, 45-48]. Therefore, co-expressing cry, cyt and tmfA in Anabaena PCC 7120 should have a potential advantage.

\section{ACKNOWLEDGEMENTS:}

This work was partially supported by the Florida Department of Agriculture and Consumers Services grant 75900 to Professor D. Borovsky, and grants 97-00081 and 2007-037 from the United States-Israel Binational Science Foundation (BSF), Jerusalem, to Professors D. Borovsky and A. Zaritsky.

\section{REFERENCES}

[1] Georghiou GP, Lagunes-Tejeda A. The occurrence of resistance to pesticides in arthropods. Rome: FAO 1991.

[2] Borovsky D, Carlson DA, Griffin PR, Shabanowitz R, Hunt DF. Mosquito oostatic factor: a novel decapeptide modulating trypsinlike enzyme biosynthesis in the midgut. FASEB J 1990; 4: 301520.

[3] Borovsky D, Janssen I, Vanden Broeck J, et al. Molecular sequencing and modeling of Neobellieria bullata trypsin: Evidence for translational control with Neb TMOF. Eur J Biochem 1996; 237: 279-87.

[4] Borovsky D, Rabindran S, Dawson WO, et al. Expression of Aedes TMOF on the virion of TMV: A potential larvicide. Proc Nat Acad Sci USA 2006; 103: 18963-8.

[5] Borovsky D. Trypsin Modulating Oostatic Factor: A Potential New Larvicide for Mosquito Control. J Exptl Biol 2003; 206: 3869-75.

[6] Borovsky D, Mahmood F. Feeding the mosquito Aedes aegypti with TMOF and its analogs; effect on trypsin biosynthesis and egg development. Regul Peptides 1995; 57: 273-81.

[7] Borovsky D, Powell CA, Nayar JK, Blalock JE, Hayes TK. Characterization and localization of mosquito-gut receptors for trypsin modulating oostatic factor (TMOF) using a complementary peptide and immunocytochemistry. FASEB J 1994; 8: 350-5.

[8] Nauwelaers S, Borovsky D. Cloning and expression of trypsin modulating oostatic factor (Aea-TMOF) and green fluorescent protein (GFP) in Saccharomyces cerevisiae. In: Konopinska D, Coast G, Goldsworthy G, Nachman RJ, Rosinski G, Eds. Arthropods 2001. Wroclaw, Poland: Wydawnictawa, Uniwersytetu Wroclawskiego 2002; 138-40.

[9] Borovsky D, Meola SM. Biochemical and Cytoimmunological Evidence for the Control of Aedes aegypti Larval Trypsin with Aea-TMOF. Arch Insect Biochem Physiol 2004; 55: 124-39.

[10] Clements AN. The biology of mosquitoes: development, nutrition and reproduction. vol 1. New York: Chapman and Hall 1992.

[11] Goldberg LJ, Margalit J. A bacterial spore demonstrating rapid larvicidal activity against Anopheles sergentii, Uranataenia unguiculata, Culex univittatus, Aedes aegypti and Culex pipiens. Mosq News 1977: 355-8.

[12] Margalith Y, Ben-Dov E. Biological Control by Bacillus thuringiensis subsp. israelensis. In: Rechcigl JE, Rechcigl NA Eds. Insect pest management: techniques for environmental protection. Boca Raton, FL, Lewis Publishers and CRC Press LLC. 2000; 243-301.

[13] Becker N, Ludwig M. Investigations on possible resistance in Aedes vexans field populations after a 10-year application of Bacillus thuringiensis israelensis. J Am Mosq Control Assoc 1993; 9: 221-4.

[14] Charles JF, Nielsen-LeRoux C. Mosquitocidal bacterial toxins: diversity, mode of action and resistance phenomena. Memorias Do Instituto Oswaldo Cruz 2000; 95: 201-6.

[15] Manasherob R, Ben-Dov E, Zaritsky A, Barak Z. Germination, growth and sporulation of Bacillus thuringiensis subsp. israelensis in excreted food vacuoles of the protozoan Tetrahymena pyriformis. Appl Environ Microbiol 1998; 64: 1750-8.

[16] Manasherob R, Ben-Dov E, Wu X, Boussiba S, Zaritsky A. Protection from UV-B damage of mosquito larvicidal toxins from 
Bacillus thuringiensis subsp. israelensis expressed in Anabaena PCC 7120. Curr Microbiol 2002; 45: 217-20.

[17] Boussiba S, Wu X-Q, Ben-Dov E, Zarka A, Zaritsky A. Nitrogenfixing cyanobacteria as gene delivery system for expressing mosquitocidal toxins of Bacillus thuringiensis ssp. israelensis. J Appl Phycol 2000; 12: 461-7.

[18] Wu X, Vennison SJ, Liu H, Ben-Dov E, Zaritsky A, Boussiba S. Mosquito larvicidal activity of transgenic Anabaena strain PCC 7120 expressing combinations of genes from Bacillus thuringiensis subsp. israelensis. Appl Environ Microbiol 1997; 63: 1533-7.

[19] Lluisma A O, Karmacharya N, Zarka A, Ben-Dov E, Zaritsky A, Boussiba S. Suitability of Anabaena PCC 7120 expressing mosquitocidal toxin genes from Bacillus thuringiensis subsp. israelensis for biotechnological application. Appl Microbiol Biotechnol 2001; 57: 161-6.

[20] Khasdan V, Ben-Dov E, Manasherob R, Boussiba S, Zaritsky A. Mosquito larvicidal activity of transgenic Anabaena PCC 7120 expressing toxin genes from Bacillus thuringiensis subsp. israelensis. FMES Microbiol Lett 2003; 227: 189-95.

[21] Sneh B, Schuster S, Gross S. Improvement of the insecticidal activity of Bacillus thuringiensis var. entomocidus on larvae of Spodoptera littoralis (Lepidoptera, Noctuidae) by addition of chitinolytic bacteria, a phagostimulant and a UV-protectant. Z Angew Entomol 1983; 96: 77-83.

[22] Regev A, Keller M, Striznov N, et al. Synergistic activity of a Bacillus thuringiensis $\delta$-endotoxins and a bacterial endochitinase against Spodoptera littoralis larvae. Appl Environ Microbiol 1996; 62: 3581-6.

[23] Sirichotpakorn N, Rongnoparut P, Choosang K, Panbangred W. Coexpression of chitinase and the cryl1Aal toxin genes in Bacillus thuringiensis serovar. israelensis. J Invertebr Pathol 2001; 78: 1609.

[24] Wolk CP, Vonshak A, Kehoe P, Elhai J. Construction of shuttle vectors capable of conjugative transfer from Escherichia coli to nitrogen-fixing filamentous cyanobacteria. Proc Natl Acad Sci USA 1984; 81: 1561-5.

[25] Laemmli, UK. Cleavage and structural proteins during the assembly of the head of bacteriophage T4. Nature (London) 1970; 227: 680-5.

[26] Ben-Dov E, Boussiba S, Zaritsky A. Mosquito larvicidal activity of Escherichia coli with combinations of genes from Bacillus thuringiensis subsp. israelensis. J Bacteriol 1995; 177: 2851-7.

[27] Khasdan V, Ben-Dov E, Manasherob R, Boussiba S, Zaritsky A. Toxicity and synergism in transgenic Escherichia coli expressing four genes from Bacillus thuringiensis subsp. israelensis. Environ Microbiol 2001; 3: 798-806.

[28] Nauwelaers S. Bioengineering of Chlorella species, Saccharomyces cerevisiae and Pichia pastoris with Aedes aegypti Trypsin Modulating Oostatic Factor (TMOF). Ph. D. Thesis. Belgium: Catholic University of Leuven 2002.

[29] Borovsky D, Powell CA, Carlson DA. Development of specific RIA and ELISA to study trypsin modulating oostatic factor in mosquitoes. Arch Insect Biochem Physiol 1992; 21: 13-21.

[30] Paul A, Harrington LC, Zhang L, Scott JG. Insecticide resistance in Culex pipiens from New York. J Am Mosq Control Assoc 2005; 21: 305-9.

[31] Wirth MC, Georghiou GP, Federici BA. CytA enables CryIV endotoxins of Bacillus thuringiensis to overcome high levels of
CryIV resistance in the mosquito Culex quinquefasciatus. Proc Natl Acad Sci USA 1997; 94: 10536-40.

[32] Porter AG, Davidson EW, Liu J-W. Mosquitocidal toxins of bacilli and their genetic manipulation for effective biological control of mosquitoes. Microbiol Rev 1993; 57: 838-61.

[33] Borovsky D, Hamdaoui A. Binding of Aedes aegypti Trypsin Modulating Oostatic Factor (Aea-TMOF) to its receptor stimulates phosphorylation and protease processing of gut-membrane proteins. Pestycydy/Pesticides 2008; 1-2: 13-26.

[34] Borovsky D, Carlson DA, Griffin PR, Shabanowitz J, Hunt DF. Mass spectrometry and characterization of Aedes aegypti Trypsin Modulating Oostatic Factor (TMOF) and its analogs. Insect Biochem Mol Biol 1993; 23: 703-12.

[35] Borovsky D, Song Q, Ma MC, Carlson DA. Biosynthesis, secretion and immunocytochemistry of trypsin modulating oostatic factor of Aedes aegypti Arch Insect Biochem Physiol 1994; 27: 27-38.

[36] Khawaled K, Barak Z, Zaritsky A. Feeding behavior of Aedes aegypti larvae and toxicity of dispersed and of naturally encapsulated Bacillus thuringiensis var. israelensis. J Invertebr Pathol 1988; 52: 419-26.

[37] Keller M, Sneh B, Striznov N, et al. Digestion of $\delta$-endotoxin by gut proteases may explain reduced sensitivity of advanced instar larvae of Spodoptera littoralis to CryIC. Insect Biochem Mol Biol 1996; 43: 29-40.

[38] Ben-Dov E, Saxena D, Wang Q, Manasherob R, Boussiba S, Yu Z, Zaritsky A. Ingested particles reduce susceptibility of insect larvae to Bacillus thuringiensis. J Appl Ent 2003, 127: 146-52.

[39] Malakhov MP, Mattern MR, Malakhova OA, Drinker M, Weeks SD, Butt TR. SUMO fusions and SUMO-specific protease for efficient expression and purification of proteins. J. Struct Funct Genomics 2004; 5: 75-86.

[40] Quintana-Castro R, Ramirez-Suero M, Moreno-Sanz F, RanirezLepe M. Expression of the cryl1A gene of Bacillus thuringiensis ssp. israelensis in Saccharomyces cerevisiae. Cana J Microbiol 2005; 51: 165-70.

[41] Ogunjimi AA, Chandler JM, Gbenle GO, Olukoya DK, Akinrimisi EO. Heterologous expression of cry2 gene from the local strain of Bacillus thurningiensis isolated in Nigeria. Biotechnol Appl Biochem 2002; 36: 241-6.

[42] Merritt RW, Dadd RH, Walker ED. Feeding behavior, natural food, and nutritional relationships of larval mosquitoes. Annu Rev Entomol 1992: 37: 349-76.

[43] Avissar VJ, Margalith Y, Spielman A. Incorporation of body components of diverse microorganisms by larval mosquitoes. J Am Mosq Control Assoc 1994; 10: 45-50.

[44] Boussiba S. Production of the nitrogen-fixing cyanobacterium Anabaena siamensis in a closed tubular reactor for rice farming. Microbial Releases 1993; 2: 35-9.

[45] Stevens SE Jr, Murphy RC, Lamoreaux WJ, Coons LB. A genetically engineered mosquitocidal cyanobacterium. J Mol Biol 1994; 6: 187-97.

[46] Shestakov SV, Khyen NT. Evidence for genetic transformation in blue-green alga Anacystis nidulns. Mol Gen Genet 1970; 107: 32775.

[47] Elhai J, Wolk CP. Conjugal transfer of DNA to cyanobacteria. Methods Enzymol 1988; 167: 747-54.

[48] Elhai J. Strong and regulated promoters in the cyanobacterium Anabaena PCC 7120. FEMS Microbiol Lett 1993; 114: 179-84. 